\title{
CIRURGIA NO PACIENTE IDOSO
}

\section{SURGERY IN THE AGED PATIENTS}

Andy Petroianu, TCBC-MG1
Em 1600, Sir Francis Bacon escreveu em seu livro, The Advancement of Learning, "...the natural dissolution and the decay of age... is a subject which no physician has handled in proportion to its dignity“. Lamentavelmente, mesmo com os grandes avanços científicos, humanísticos e médicos dos últimos 400 anos, essa afirmação continua válida em sua plenitude. A qualidade de nosso mundo é uma herança em vida dos idosos, porém a sociedade ainda não alcançou o desenvolvimento moral suficiente para compreender a realidade $\mathrm{e}$ atender às necessidades dos seus construtores, para proporcionar-lhes o respeito, os cuidados e o conforto que lhes são devidos por direito. Já é grande demais o castigo natural imposto à maior parte dos idosos pela progressiva dependência decorrente de suas limitações físicas, mentais e financeiras.

A camada social chamada de "terceira idade" vem crescendo progressivamente e há uma perspectiva segura de que duplicará em menos de trinta anos. Atualmente, ela é responsável por $42 \%$ das consultas médicas e metade das internações hospitalares. Portanto, é inevitável uma preocupação especial com as pessoas dessa faixa etária, pois elas são portadoras da maior parte das enfermidades. Em geral, os idosos toleram bem o trauma cirúrgico, quando seus distúrbios orgânicos são bem controlados. Os maiores riscos decorrem de complicações operatórias e de procedimentos emergenciais, cuja mortalidade pode alcançar $35 \%$, enquanto apenas $8 \%$ dos muito idosos vão a óbito após tratamentos cirúrgicos eletivos. Apesar de as pessoas com mais de 70 anos serem submetidas a um número maior de operações programadas e evoluírem com mais adversidades do que as mais jovens, a mortalidade pós-operatória aumenta somente após os 80 anos. Em idade muito avançada, o óbito resulta da insuficiência orgânica natural agravada pelo trauma operatório, enquanto grande parte dos óbitos em todas as faixas etárias é provocada por complicações e comorbidades.

Os conhecimentos médico-científicos derrubaram o conceito de que a velhice é um estado de deterioração orgânica do adulto, assim como não faz mais sentido pensar na criança como um adulto em miniatura. $\mathrm{O}$ idoso apresenta características anatômicas, fisiológicas e bioquímicas próprias, em parte determinadas geneticamente. Assim sendo, deve-se conhecer seus aspectos orgânicos e psíquicos, tanto quanto seus distúrbios patológicos. Essas condições assumem proporções ainda maiores, quando se acrescenta a resposta orgânica à agressão operatória.
Ao iniciar o relacionamento com um paciente idoso, é preciso dar-se conta de estar diante de uma pessoa astuta, discreta, com grande apreço por sua dignidade, além de corajosa, persistente e com muito amor à vida. Há alguns ditos populares interessantes sobre os idosos, que valem uma reflexão maior, como "mais sabe o diabo por ser velho, do que por ser diabo" e "o diabo não é esperto por ser diabo, mas por ser velho". A necessidade de auto-afirmação sem alicerce, explícita nos jovens, deixa de ter importância com o avançar dos anos e o idoso, apesar de saber muito, por estudo e experiências vividas, não revela, sem propósito, seus conhecimentos nem suas percepções, na maioria das vezes, corretas. Todo médico precisa entender que é o paciente idoso, e não o jovem acompanhante, quem sabe sobre a sua enfermidade $\mathrm{e}$ conversar diretamente com seu doente, estimulando-o, com delicadeza, a falar, pois, caso contrário, ele irá manter-se discretamente calado, mas tendo claro o despreparo de quem se propõe a cuidar dele.

A maioria das doenças crônicas de tratamento cirúrgico ocorre nos idosos e o médico que tiver habilidade é capaz de operar adequadamente o paciente geriátrico. Contudo, cabe ressaltar que Cirurgia é muito mais do que técnica e o cirurgião deve aliar o profundo conhecimento clínico em sua especialidade à sensibilidade para notar as restrições físicas e psíquicas do paciente fragilizado pelo tempo e, muitas vezes, pelas condições adversas familiares, sociais e econômicas. No ato operatório, é preciso levar em conta as limitações do doente e optar pelo melhor tratamento por ele tolerado. O compromisso é com o paciente e não com o tratamento. A pessoa com idade avançada possui pouca reserva orgânica para reagir a um procedimento cirúrgico muito agressivo, mesmo com intenção de cura. $\mathrm{O}$ risco do tratamento jamais deve ultrapassar o da doença e é mais conveniente realizar um procedimento para melhorar a qualidade de vida do que tentar a cura com risco elevado de sofrimento, seguido de morte.

Existe uma tendência de os familiares e as pessoas próximas dos idosos menosprezarem as suas queixas, seja por considerarem o ancião excessivamente lamuriento, seja por não assumirem a gravidade da doença em um ente muito querido. Por outro lado, a pessoa de idade avançada pode não revelar seus sofrimentos, por orgulho ou por indignação com a indiferença de quem as rodeia. As reclamações insistentes são a maneira de o idoso sem autonomia pedir ajuda para viver mais e com menos sofrimento.

1. Professor Titular do Departamento de Cirurgia da Faculdade de Medicina, UFMG; Docente Livre em Técnica Operatória e Cirurgia Experimental da Escola Paulista de Medicina, UNIFESP; Docente Livre em Gastroenterologia Cirúrgica da Faculdade de Medicina de Ribeirão Preto, USP; Doutor em Fisiologia e Farmacologia - Instituto de Ciências Biológicas, UFMG, Pesquisador IA do CNPq, Membro Titular da Academia Mineira de Medicina. 
Pelo desgaste natural do organismo, surgem, lenta e progressivamente, distúrbios em quase todos os órgãos e sistemas. É fundamental acreditar em todos os relatos do paciente, para detectar afecções não apenas relacionadas à doença cirúrgica, mas também a outras moléstias menos valorizadas, que podem levar o ato operatório para uma evolução desfavorável. Os problemas complexos iniciam como pequenos distúrbios, com manifestações eventualmente incomuns. Nesse sentido, os exames complementares estão entre as principais causas de confusão diagnóstica, pois, no idoso, não é raro eles indicarem valores normais, em presença de doença grave, ou estarem alterados, sem substratos patológicos. Nesses pacientes não há complicação menor, pois, ao contrário do jovem, que suporta bem adversidades, neles, todos os infortúnios cirúrgicos podem tornar-se fatais.

A expectativa de vida e a evolução natural para a morte não é assunto para ser levado em conta, principalmente com quem alcançou idade avançada, por ter vontade de viver. Cabe ao profissional contribuir para a sobrevivência do paciente, oferecendo-lhe a melhor qualidade de vida possível, enquanto ele se mantiver sob seus cuidados. A opção de interromper o tratamento ou abandonar o médico deve ser apenas do paciente.

Está também inserido no papel do profissional da saúde proporcionar ao doente o máximo de conforto e proteção. É importante lembrar que as mesas de exame e os leitos hospitalares precisam ser baixos, para o paciente sentar-se e deitar-se sem o desconforto e o perigo das escadinhas. A mobilização do idoso também precisa ser muito cuidadosa, pelo elevado risco de fraturas e luxações, em decorrência de osteoporose e afecções articulares. Parte dos óbitos deve-se às complicações advindas da imobilização, para tratar fraturas ou luxações, por vezes, iatrogênicas.
De igual importância ao ato operatório é o zelo em torno da operação, que é de responsabilidade total do cirurgião. A preocupação com o estado nutricional é prioritária, tendo em vista as dificuldades de o idoso alimentar-se, por inapetência, problemas dentários e de salivação, além de distúrbios motores esofágicos e gástricos. Essa desnutrição pode estar camuflada por aparente obesidade.

A hidratação é outro aspecto perioperatório relevante, pois o idoso tende à desidratação fisiológica, para não sobrecarregar o sistema cardiopulmonar. Percebe-se, assim, a necessidade de um conhecimento maior para manter o equilíbrio hidroeletrolítico, além do endocrinometabólico, uma vez que, com o avançar da idade, o declínio orgânico acompanhase de diabetes, hipotireoidismo e insuficiência supra-renal, entre outros distúrbios com repercussão desfavorável à boa evolução do paciente cirúrgico.

Operar o idoso, com todas as suas particularidades, é uma nobre e nada fácil tarefa. Ela encerra em si o resgate e o tributo ao forte que se tornou dependente, para permitir-lhe usufruir, durante mais algum tempo, da obra por ele composta. A persistência na educação continuada em cirurgia geriátrica, além da profunda satisfação de um dever cumprido, irá gerar frutos, parte dos quais poderá reverter, no futuro, até em benefício em causa própria.

Endereço para correspondência:

Prof. Andy Petroian

Avenida Afonso Pena, 1626 - apto. 1901

30130-005 - Belo Horizonte - MG

TELEFONE / FAX : (31) 3274-7744 e 8884-9192

E-mail:petroian@gmail.com 